\title{
Associations of GNAS Mutations with Surgical Outcomes in Patients with Growth Hormone-Secreting Pituitary
} Adenoma

\author{
Hyein Jung ${ }^{1,2}$, Kyungwon Kim¹, Daham Kim ${ }^{1}$ Ju Hyung Moon ${ }^{3}$, Eui Hyun Kim³, Se Hoon Kim, Cheol Ryong Ku¹, \\ Eun Jig Lee ${ }^{1}$ \\ ${ }^{1}$ Division of Endocrinology, Department of Internal Medicine, Yonsei University College of Medicine; ${ }^{2}$ Department of Internal \\ Medicine, Ewha Womans University School of Medicine; Departments of ${ }^{3}$ Neurosurgery, ${ }^{4}$ Pathology, Yonsei University College \\ of Medicine, Seoul, Korea
}

Background: The guanine nucleotide-binding protein, alpha stimulating (GNAS) gene has been associated with growth hormone (GH)-secreting pituitary adenoma. We investigated the prevalence of GNAS mutations in Korean patients with acromegaly and assessed whether mutation status correlated with biochemical or clinical characteristics.

Methods: We studied 126 patients with acromegaly who underwent surgery between 2005 and 2014 at Severance Hospital. We performed GNAS gene analysis and evaluated age, sex, hormone levels, postoperative biochemical remission, and immunohistochemical staining results of the tumor.

Results: GNAS mutations were present in 75 patients (59.5\%). Patients with and without GNAS mutations showed similar age distribution and Knosp classification. The proportion of female patients was $76.5 \%$ and $48.0 \%$ in the $G N A S$-negative and $G N A S$-mutation groups, respectively $(P=0.006)$. In immunohistochemical staining, the $G N A S$-mutation group showed higher GH expression in pituitary tumor tissues than the mutation-negative group $(98.7 \%$ vs. $92.2 \%, P=0.015)$. Patients with $G N A S$ mutations had higher preoperative insulin-like growth factor-1 levels $(791.3 \mathrm{ng} / \mathrm{mL}$ vs. $697.0 \mathrm{ng} / \mathrm{mL}, P=0.045)$ and lower immediate postoperative basal $(0.9$ $\mathrm{ng} / \mathrm{mL}$ vs. $1.0 \mathrm{ng} / \mathrm{mL}, P=0.191)$ and nadir GH levels $(0.3 \mathrm{ng} / \mathrm{mL}$ vs. $0.6 \mathrm{ng} / \mathrm{mL}, P=0.012)$ in oral glucose tolerance tests. Finally, the GNAS-mutation group showed significantly higher surgical remission rates than the mutation-negative group, both at 1 week and 6 months after surgical resection ( $70.7 \%$ vs. $54.9 \%, P=0.011 ; 85.3 \%$ vs. $82.4 \%, P=0.007$, respectively).

Conclusion: GNAS mutations in GH-secreting pituitary tumors are associated with higher preoperative insulin-like growth factor-1 levels and surgical remission rates and lower immediate postoperative nadir GH levels. Thus, GNAS mutation status can predict surgical responsiveness in patients with acromegaly.

Keywords: Acromegaly; GTP-binding protein alpha subunits; Growth hormone; Insulin-like growth factor I

Received: 14 October 2020, Revised: 16 December 2020,

Accepted: 4 January 2021

Corresponding authors: Eun Jig Lee

Division of Endocrinology, Department of Internal Medicine, Institute of

Endocrine Research, Yonsei University College of Medicine, 50-1 Yonsei-ro,

Seodaemun-gu, Seoul 03722, Korea

Tel: +82-2-2228-0833, Fax: +82-2-393-6884, E-mail: ejlee423@yuhs.ac

Cheol Ryong $\mathrm{Ku}$

Division of Endocrinology, Department of Internal Medicine, Institute of

Endocrine Research, Yonsei University College of Medicine, 50-1 Yonsei-ro,

Seodaemun-gu, Seoul 03722, Korea

Tel: +82-2-2228-0872, Fax: +82-2-393-6884, E-mail: cr079@yuhs.ac

\section{Copyright $@ 2021$ Korean Endocrine Society}

This is an Open Access article distributed under the terms of the Creative Commons Attribution Non-Commercial License (https://creativecommons.org/ licenses/by-nc/4.0/) which permits unrestricted non-commercial use, distribution, and reproduction in any medium, provided the original work is properly cited. 


\section{INTRODUCTION}

Acromegaly is a chronic disorder resulting from an excess of growth hormone $(\mathrm{GH})$, and it is most commonly caused by GHsecreting pituitary adenomas. Hypersecretion of GH results in increased production of insulin-like growth factor-1 (IGF-1), leading to a multisystem disease characterized by somatic overgrowth, multiple comorbidities, and premature mortality $[1,2]$.

Acromegaly is a rare disease and related genes have been studied. Although most cases of acromegaly occur sporadically, more than $50 \%$ of cases of childhood-onset acromegaly are associated with a genetic cause. Several germline mutations are associated with acromegaly, including those in multiple endocrine neoplasia type 1 (MEN1), protein kinase A regulatory subunit $1 \alpha$ (PRKARIA), aryl hydrocarbon receptor-interacting protein (AIP), and G-protein coupled receptor 101 (GPR101) genes. X-linked acrogigantism and a few related somatic mutations have also been reported [3-5]. The most commonly identified somatic mutations in acromegaly are activating mutations of the guanine nucleotide-binding protein, alpha stimulating $(G N A S)$ gene [6]. A gain-of-function mutation in GNAS increases cyclic adenosine monophosphate (cAMP) synthesis and results in increased cell proliferation and GH secretion. Hotspot mutations in GNAS have been identified at codon 201, wherein arginine is replaced by cysteine, histidine, or serine, and in codon 227, wherein glutamine is replaced by arginine or leucine [7,8]. Approximately $30 \%$ to $40 \%$ of patients with sporadic acromegaly have GNAS mutations [6]. Patients with acromegaly with GNAS mutations tend to have high GH and IGF-1 levels and show a favorable response to somatostatin analogs (SSAs) $[9,10]$.

However, limited data have been reported for Asian populations. The prevalence of these mutations varies according to patient cohorts, ranging from $4.4 \%$ in Japanese patients [11] to $55 \%$ in Chinese patients [12]. In addition, many studies on the clinical outcomes of acromegaly associated with GNAS mutations have been conducted; however, only a few have analyzed the relationship between the surgical remission rate and GNAS mutations. Therefore, in this study, we investigated the prevalence of GNAS mutations in Korean patients with acromegaly and assessed whether mutation status correlated with biochemical or clinical characteristics. Furthermore, we analyzed the relationship between the surgical remission rate and GNAS mutations.

\section{METHODS}

\section{Study population}

We enrolled Korean patients with acromegaly who underwent transsphenoidal adenomectomy (TSA) between January 2005 and May 2014 at Severance Hospital, Seoul, South Korea. Patients with a family history or germline mutation were excluded. All TSAs were performed by one neurosurgeon (S.H.K.). In total, 138 patients were enrolled and 12 of them were excluded because of insufficient DNA for analysis (Fig. 1).

Clinical data were retrospectively collected from patients' medical records. Pituitary tumors were classified based on the dynamic magnetic resonance imaging (MRI) of the sellar and parasellar regions based on the Knosp classification. According to a previous study [13,14], Knosp grades 3 and 4 were classified as having cavernous sinus invasion. Tumor size was determined from the preoperative MRI report and recorded as the maximal tumor diameter. Immunohistochemical (IHC) staining of the operated pituitary tumors was performed, following which they were classified as focal GH, weak GH, and GH by two pathologists. Focal GH was defined as the expression of $\mathrm{GH}$ in less than $10 \%$ of the total tumor area, and weak GH was defined as low GH expression compared to the surrounding normal GH-secreting cells. The other tumors were classified as GH. Proliferative activity of the tumor cells was determined by calculating the percentage of cells exhibiting the $\mathrm{Ki}-67$ antigen. As the Ki-67 index was measured from 2010 onwards, only the

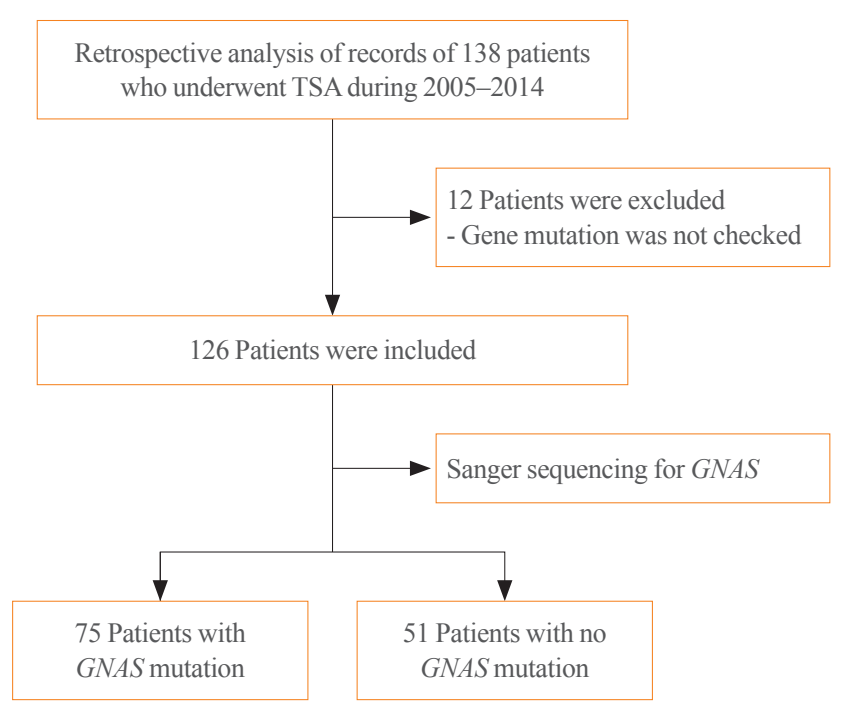

Fig. 1. Flow chart of the study population. TSA, transsphenoidal adenomectomy; GNAS, guanine nucleotide-binding protein, alpha stimulating. 
data from 97 patients who underwent surgery after 2010 were analyzed.

Immediate postoperative dynamic MRI of the sella was conducted within 48 hours after TSA to determine whether surgical resection was complete, and the postoperative MRI findings were compared with those of MRI conducted 1 year following TSA. Subsequently, MRI was performed annually to find any evidence of recurrence and every 2 or 3 years if the patient achieved biochemical remission. Surgical remission was defined as a nadir serum $\mathrm{GH}$ level of $<1 \mathrm{ng} / \mathrm{mL}$ based on the result of the 75-g oral glucose tolerance test (OGTT), and ageand sex-matched normal IGF-1 levels. This study was approved by the Institutional Review Board of the Yonsei University College of Medicine (4-2019-1185). Informed consent was obtained from all individual participants included in this study.

\section{Endocrinological evaluation}

Before surgery, serum GH and IGF-1 levels were measured from serum obtained during the 75-g OGTT. OGTT was performed 1 week after TSA, every 6 months for 3 years, and then annually. Before February 2010, GH levels were measured using an immunoradiometric assay (hGH 100T Kit, Nichols Institute, San Juan Capistrano, CA, USA) with a sensitivity of 0.02 $\mathrm{ng} / \mathrm{mL}$. The within-assay coefficient of variation (CV) ranged from $2.8 \%$ to $4.2 \%$, and the interassay $\mathrm{CV}$ varied from $3.5 \%$ to 7.2\%. After February 2010, GH levels were measured using an immunoradiometric assay (hGH-RIACT, CIS Bio International, Gif-sur-Yvette, France) with a sensitivity of $0.03 \mathrm{mIU} / \mathrm{mL}$. The within-assay $\mathrm{CV}$ ranged from $1.3 \%$ to $2.1 \%$, and the interassay CV varied from $3.8 \%$ to $5.0 \%$. The World Health Organization's international standard $(98 / 574)$ was used to measure the GH level.

Before July 2005, IGF-1 levels were measured using an immunoradiometric assay system (DSL-5600 Active, Diagnostic Systems Laboratories, Webster, TX, USA) with $0.80 \mathrm{ng} / \mathrm{L}$ sensitivity. The within-assay CV ranged from $1.5 \%$ to $3.4 \%$, and the interassay CV varied from $1.5 \%$ to $8.2 \%$. After July 2005 , IGF-1 levels were measured using an immunoradiometric assay system (IGF-1 NEXT IRMA CT, Biocode Hycel, Liège, Belgium), with a minimum detectable IGF-1 concentration of 1.25 $\mathrm{ng} / \mathrm{L}$. The interassay and within-assay $\mathrm{CV}$ ranges of IGF-1 were $7.4 \%$ to $9.1 \%$ and $2.6 \%$ to $4.4 \%$, respectively [15].

\section{GNAS gene analysis}

Tumor DNA was extracted using QIAamp DNA FFPE Tissue Kit (50) according to the manufacturer's instructions. GNAS gene analysis was performed by amplifying the regions containing two sites of activating somatic mutations in codons 201 and 227 using primers (forward: GCTTCCTGGACAAGATCGAC, reverse: CTCCACAAACCTGTTGTTCCA; short forward: GCCGAGCGATCAGGTGTG; short reverse: GGAAGTTGACTTTGTCCACC) designed to cover both hotspot mutations.

The following polymerase chain reaction thermocycling conditions were used: initial denaturation at $94^{\circ} \mathrm{C}$ for 5 minutes, followed by 35 cycles of denaturation at $94^{\circ} \mathrm{C}$ for 30 seconds, annealing at $58^{\circ} \mathrm{C}$ for 1 minute, extension at $72^{\circ} \mathrm{C}$ for 1 minute, and a final extension step at $72^{\circ} \mathrm{C}$ for 7 minutes. Gene mutations were evaluated by conventional Sanger sequencing.

\section{Statistical analysis}

SPSS Statistics version 25 (IBM Corp., Armonk, NY, USA) was used for all statistical analyses. Continuous variables are expressed as median (interquartile range [IQR]). The MannWhitney $U$ test was used for the analysis of continuous variables to compare groups based on gene mutations. Categorical variables were analyzed using the Fisher exact test. Multivariate binary logistic regression analysis was performed to analyze risk factors associated with surgical remission in patients with acromegaly. A $P$ value $<0.05$ was considered to indicate statistical significance.

\section{RESULTS}

\section{Baseline characteristics of the study population}

The characteristics of the 126 patients are shown in Table 1 . The median age was 42 years (IQR, 35 to 50 ) at diagnosis, and $60 \%$ of the patients were female. The median tumor size was $15 \mathrm{~mm}$. The median follow-up duration after TSA was 75.5 months (IQR, 63.3 to 97.4). Total removal after TSA was achieved in $91.3 \%$ of patients, while subtotal removal was achieved in $8.7 \%$ of patients. Most of the tumors (95.2\%) were GH-positive in IHC staining.

Patients were classified according to the presence of GNAS mutations and their clinical characteristics were compared. GNAS mutations were present in 75 of the 126 acromegaly patients $(59.5 \%)$. Of the GNAS mutations, $86.7 \%$ were located at codon 201, while the rest of them were located at codon 227. Patients with and without GNAS mutations were similar with regard to age distribution and Knosp classification. The mutation-negative group was $76.5 \%$ female, and the mutation-positive group was $48.0 \%$ female $(P=0.006)$. There was no significant difference in tumor size according to GNAS mutations. No- 


\begin{tabular}{|c|c|c|c|c|}
\hline \multirow{2}{*}{ Characteristic } & \multirow{2}{*}{ Total } & \multicolumn{2}{|c|}{ GNAS mutation } & \multirow{2}{*}{$P$ value } \\
\hline & & No mutation & Mutation & \\
\hline No. of patients & 126 & $51(40.5)$ & $75(59.5)$ & \\
\hline Age, yr & $42(35-50)$ & $43(36-53)$ & $41(34-48)$ & 0.098 \\
\hline Sex & & & & 0.006 \\
\hline Male & $51(40.5)$ & $12(23.5)$ & $39(52.0)$ & \\
\hline Female & $75(59.5)$ & $39(76.5)$ & $36(48.0)$ & \\
\hline Follow-up duration, mo & $75.5(63.3-97.4)$ & $73.4(52.5-95.9)$ & $86.0(69.8-99.8)$ & 0.051 \\
\hline Size, mm & $15(10.75-20.0)$ & $15(12-23)$ & $14(10-18)$ & 0.052 \\
\hline Knosp classification & & & & 0.100 \\
\hline 0 & $18(14.3)$ & $5(9.8)$ & $13(17.3)$ & \\
\hline 1 & $48(38.1)$ & $21(41.2)$ & $27(36.0)$ & \\
\hline 2 & $41(32.5)$ & $13(25.5)$ & $28(37.3)$ & \\
\hline $3 a$ & $12(9.5)$ & $6(11.8)$ & $6(8.0)$ & \\
\hline $3 b$ & $1(0.8)$ & $1(2.0)$ & 0 & \\
\hline 4 & $6(4.8)$ & $5(9.8)$ & $1(1.3)$ & \\
\hline Immunohistochemical staining & & & & 0.015 \\
\hline Focal GH & $1(0.8)$ & $1(2.1)$ & 0 & \\
\hline Weak GH & $5(4.0)$ & $3(5.9)$ & $2(2.6)$ & \\
\hline $\mathrm{GH}$ & $120(95.2)$ & $47(92.2)$ & $73(97.3)$ & \\
\hline Ki-67 staining, \% & 97 & 41 & 56 & 0.604 \\
\hline$<1$ & 44 & 20 & 24 & \\
\hline $1-2$ & 38 & 14 & 24 & \\
\hline $2-3$ & 13 & 7 & 6 & \\
\hline$>3$ & 2 & 0 & 2 & \\
\hline
\end{tabular}

Values are expressed as number (\%) or median (interquartile range).

$G N A S$, guanine nucleotide-binding protein, alpha stimulating; $\mathrm{GH}$, growth hormone.

tably, the GNAS mutation-positive group had a higher prevalence of GH positivity in IHC staining than the mutation-negative group $(97.3 \%$ vs. $92.2 \%, P=0.015)$.

\section{Immediate postoperative biochemical remission}

The median preoperative serum GH and IGF-1 levels were 15.1 and $753.1 \mathrm{ng} / \mathrm{mL}$, respectively (Table 2). One week after TSA, the median nadir GH level during OGTT was $0.4 \mathrm{ng} / \mathrm{mL}$ and the median IGF-1 level was $342.1 \mathrm{ng} / \mathrm{mL}$. Six months after TSA, the median nadir GH level during OGTT was $0.9 \mathrm{ng} / \mathrm{mL}$, and the median IGF-1 level was $250.3 \mathrm{ng} / \mathrm{mL}$.

The median preoperative serum GH levels were similar in the mutation-positive and -negative groups $(14.7 \mathrm{ng} / \mathrm{mL}$ vs. 16.1 $\mathrm{ng} / \mathrm{mL}$, respectively). The median preoperative IGF-1 level was significantly higher in the mutation-positive group than in the mutation-negative group $(770.9 \mathrm{ng} / \mathrm{mL}$ vs. $697.0 \mathrm{ng} / \mathrm{mL}$, respectively; $P=0.045$ ).

Immediately after TSA, median basal GH and nadir GH levels on OGTT were lower in the GNAS mutation-positive group than in the mutation-negative group. The median immediate postoperative IGF-1 level was not significantly different between the mutation-positive $(336.0 \mathrm{ng} / \mathrm{mL})$ and mutation-negative $(348.3 \mathrm{ng} / \mathrm{mL})$ groups $(P=0.393)$. Six months after TSA, the median postoperative IGF-1 level decreased further compared to that immediately after TSA (mutation-positive group $254.8 \mathrm{ng} / \mathrm{mL}$ vs. mutation-negative group $243.3 \mathrm{ng} / \mathrm{mL}, P=$ 0.767 ) (Table 2). Median GH levels immediately after TSA-in particular, the levels at 24, 48, and 72 hours after TSA-were significantly lower in the GNAS mutation-positive group than in the mutation-negative group (Table 3). 


\begin{tabular}{|c|c|c|c|c|}
\hline \multirow{2}{*}{ Variable } & \multirow{2}{*}{ Total } & \multicolumn{2}{|c|}{ GNAS mutation } & \multirow{2}{*}{$P$ value } \\
\hline & & No mutation & Mutation & \\
\hline TSA, total/subtotal & $115(91.3) / 11(8.7)$ & $43(84.3) / 8(15.7)$ & $72(96.0) / 3(4.0)$ & 0.075 \\
\hline \multicolumn{5}{|l|}{ Preoperative OGTT } \\
\hline Basal GH, ng/mL & $15.1(6.9-32.3)$ & $16.1(5.9-32.2)$ & $14.7(7.5-32.4)$ & 0.785 \\
\hline Nadir GH, ng/mL & $11.0(5.1-23.8)$ & $8.7(4.6-23.3)$ & $11.4(6.0-24.3)$ & 0.380 \\
\hline IGF-1, ng/mL & $753.1(600.0-899.2)$ & $697.0(561.2-884.4)$ & $770.9(647.0-903.5)$ & 0.045 \\
\hline \multicolumn{5}{|c|}{ Immediate postoperative OGTT } \\
\hline Basal GH, ng/mL & $0.9(0.5-1.8)$ & $1.0(0.6-2.6)$ & $0.9(0.4-1.7)$ & 0.191 \\
\hline Nadir GH, ng/mL & $0.4(0.1-0.9)$ & $0.6(0.2-1.5)$ & $0.3(0.1-0.7)$ & 0.012 \\
\hline IGF-1, ng/mL & $342.1(280.9-467.6)$ & $336.0(256.4-494.9)$ & $348.3(292.9-435.8)$ & 0.393 \\
\hline Remission & $81(64.3)$ & $28(54.9)$ & $53(70.7)$ & 0.011 \\
\hline \multicolumn{5}{|c|}{ Postoperative OGTT at 6 mo } \\
\hline Basal GH, ng/mL & $0.13(0.1-0.3)$ & $1.1(0.4-2.6)$ & $0.7(0.1-2.1)$ & 0.125 \\
\hline Nadir GH, ng/mL & $0.9(0.2-2.5)$ & $0.15(0.1-0.3)$ & $0.12(0.1-0.3)$ & 0.305 \\
\hline IGF-1, ng/mL & $250.3(205.3-322.9)$ & $243.3(202.0-318.7)$ & $254.8(211.3-324.8)$ & 0.767 \\
\hline Remission & $106(84.1)$ & $42(82.4)$ & $64(85.3)$ & 0.007 \\
\hline
\end{tabular}

Table 3. Changes in Immediate Postoperative Growth Hormone Levels

\begin{tabular}{|c|c|c|c|}
\hline \multirow{2}{*}{ Variable } & \multicolumn{2}{|c|}{ GNAS mutation } & \multirow{2}{*}{$P$ value } \\
\hline & No mutation & Mutation & \\
\hline \multicolumn{4}{|c|}{$\begin{array}{l}\text { Postoperative growth } \\
\text { hormone levels }\end{array}$} \\
\hline $0 \mathrm{hr}$ & $2.00(1.20-5.04)$ & $2.70(1.00-8.50)$ & 0.648 \\
\hline $12 \mathrm{hr}$ & $0.95(0.45-1.78)$ & $0.70(0.40-1.33)$ & 0.131 \\
\hline $24 \mathrm{hr}$ & $1.10(0.48-1.94)$ & $0.68(0.42-1.27)$ & 0.047 \\
\hline $48 \mathrm{hr}$ & $1.08(0.52-1.89)$ & $0.70(0.38-1.20)$ & 0.043 \\
\hline $72 \mathrm{hr}$ & $0.99(0.53-1.90)$ & $0.74(0.33-1.22)$ & 0.011 \\
\hline
\end{tabular}

Values are expressed as median (interquartile range).

$G N A S$, guanine nucleotide-binding protein, alpha stimulating.

\section{Long-term surgical outcomes}

The surgical remission rate was $64.3 \%$ immediately after TSA and $84.1 \%$ at 6 months after TSA. The surgical remission rate immediately after TSA was higher in the GNAS mutation-positive group than in the mutation-negative group $(70.7 \%$ vs. $54.9 \%, P=0.011$ ). Similarly, the surgical remission rate at 6 months after TSA was higher in the mutation-positive group than in the mutation-negative group ( $85.3 \%$ vs. $82.4 \%, P=0.007)$.

Six months after TSA, 20 patients were not cured. Patients with residual tumors were treated with gamma knife radiosurgery (GKS) and medications such as SSAs or dopamine agonists. When followed up in July 2019, eight patients were still on medication (Table 4). Of these, three patients with a GNAS mutation were treated with cabergoline, which controlled the small remnant tumor well, and five with no GNAS mutation were treated with GKS, reoperation, and SSAs. The statistical significance of the results is unclear because of the small number of patients.

\section{Changes in other pituitary hormones after TSA}

At 6 months after TSA, normal pituitary function was maintained in 52 patients $(41.2 \%)$ and improvement of preoperative hypopituitarism was noted in 59 patients (46.8\%). Hypopituitarism persisted in six patients $(4.7 \%)$ and became aggravated in nine patients (7.1\%). Hormonal changes were not related to the presence of a GNAS mutation $(P=0.112)$.

\section{Recurrence}

During the follow-up period, three patients without a GNAS 
Table 4. Baseline Characteristics of Patients Who Received Medications after Surgery

\begin{tabular}{|c|c|c|c|c|c|c|c|c|c|c|}
\hline No. & $\begin{array}{l}\text { Age, yr/ } \\
\text { Sex }\end{array}$ & $\begin{array}{l}\text { GNAS } \\
\text { mutation }\end{array}$ & $\begin{array}{l}\text { Tumor } \\
\text { size, } \\
\text { mm }\end{array}$ & $\begin{array}{c}\text { Knosp } \\
\text { classification }\end{array}$ & $\begin{array}{l}\text { Initial GH, } \\
\text { ng/mL }\end{array}$ & $\begin{array}{l}\text { Initial IGF-1, } \\
\text { ng/mL }\end{array}$ & $\begin{array}{l}\text { Last } \mathrm{GH}, \\
\mathrm{ng} / \mathrm{mL}\end{array}$ & $\begin{array}{l}\text { Last IGF-1, } \\
\mathrm{ng} / \mathrm{mL}\end{array}$ & $\begin{array}{c}\text { Remnant } \\
\text { tumor on } \\
\text { MRI }\end{array}$ & Treatment \\
\hline 1 & $44 / \mathrm{F}$ & Yes & 20 & 2 & 35.85 & $1,015.7$ & 0.46 & 229.4 & No & Cabergoline $2 \mathrm{mg} / \mathrm{wk}$ \\
\hline 2 & $39 / \mathrm{M}$ & Yes & 12 & $3 a$ & 24.5 & 1,423 & 0.5 & 323 & No & Cabergoline $2 \mathrm{mg} / \mathrm{wk}$ \\
\hline 3 & $36 / F$ & Yes & 19 & 0 & 23.6 & 852.8 & 0.99 & 296.8 & No & Cabergoline $2 \mathrm{mg} / \mathrm{wk}$ \\
\hline 4 & $50 / \mathrm{F}$ & No & 12 & 1 & 18.3 & 398.5 & 1 & 297 & No & Octreotide LAR $20 \mathrm{mg}$ every $4 \mathrm{wk}$ \\
\hline 5 & $36 / F$ & No & 30 & 4 & 19.29 & 884.4 & 0.96 & 263.8 & Yes & $\mathrm{GKS} \rightarrow$ cabergoline $2 \mathrm{mg} / \mathrm{wk}$ \\
\hline 6 & $39 / \mathrm{M}$ & No & 35 & 4 & 70.8 & 774.1 & 1.7 & 365.1 & Yes & $\begin{array}{l}\text { GKS } \rightarrow \text { octreotide LAR } 20 \text { mg } \\
\text { every } 4 \text { wk }\end{array}$ \\
\hline 7 & $58 / \mathrm{F}$ & No & 20 & 4 & 5.9 & 555.6 & 0.77 & 193.2 & Yes & $\begin{array}{l}\mathrm{GKS} \rightarrow \text { lanreotide autogel } 60 \mathrm{mg} \\
\text { every } 4 \mathrm{wk}\end{array}$ \\
\hline 8 & $29 / F$ & No & 30 & 2 & 27.63 & $1,036.8$ & 2.1 & 273.9 & Yes & $\begin{array}{l}\text { Reoperation, GKS } \rightarrow \text { octreotide } \\
\text { LAR } 30 \mathrm{mg} \text { every } 4 \mathrm{wk}\end{array}$ \\
\hline
\end{tabular}

GNAS, guanine nucleotide-binding protein, alpha stimulating; GH, growth hormone; IGF-1, insulin-like growth factor-1; MRI, magnetic resonance imaging; LAR, long-acting release; GKS, gamma knife radiosurgery.

Table 5. Factors Associated with Surgical Remission in Patients with Acromegaly

\begin{tabular}{|c|c|c|}
\hline Factor & OR $(95 \% \mathrm{CI})$ & $P$ value \\
\hline Age, /1 year increment & $0.984(0.897-1.079)$ & 0.731 \\
\hline \multicolumn{3}{|l|}{ Sex } \\
\hline Male & Reference & \\
\hline Female & $1.577(0.262-9.481)$ & 0.619 \\
\hline $\begin{array}{l}\text { Preoperative random } \mathrm{GH}, \\
/ 1 \mathrm{ng} / \mathrm{mL} \text { increment }\end{array}$ & $0.913(0.784-1.064)$ & 0.243 \\
\hline $\begin{array}{l}\text { Preoperative OGTT nadir GH, } \\
/ 1 \mathrm{ng} / \mathrm{mL} \text { increment }\end{array}$ & $1.110(0.941-1.309)$ & 0.214 \\
\hline $\begin{array}{l}\text { Preoperative IGF-1, } \\
/ 1 \mathrm{ng} / \mathrm{mL} \text { increment }\end{array}$ & $1.004(1.000-1.008)$ & 0.034 \\
\hline \multicolumn{3}{|l|}{ Knosp classification } \\
\hline Grade $0-2$ & Reference & \\
\hline Grade 3-4 & $1.004(0.118-8.567)$ & 0.997 \\
\hline \multicolumn{3}{|l|}{ Cavernous sinus invasion } \\
\hline No invasion & Reference & \\
\hline Invasion & $6.202(1.192-32.262)$ & 0.030 \\
\hline \multicolumn{3}{|l|}{ GNAS mutation } \\
\hline No mutation & Reference & \\
\hline Mutation & $0.192(0.035-1.058)$ & 0.058 \\
\hline
\end{tabular}

OR, odds ratio; CI, confidence interval; GH, growth hormone; OGTT, oral glucose tolerance test; IGF-1, insulin-like growth factor-1; GNAS, guanine nucleotide-binding protein, alpha stimulating.

mutation showed recurrence of acromegaly. The first case was a 29-year-old female patient who underwent subtotal adenomec- tomy and continued medication. However, the size of the residual tumor increased, as shown in an MRI scan. She underwent GKS and is still on medication. The second case was a 38-yearold female patient, who underwent total resection; however, 1 year after TSA, a recurrent tumor was observed in an MRI scan. The third case was a 31-year-old female patient who was cured after TSA, but a newly developed tumor was found in a followup MRI scan. The second and third cases also underwent GKS. There was no recurrence in the GNAS-mutation group.

\section{Factors associated with surgical remission in acromegaly patients}

Multivariate logistic regression analysis was used to analyze the factors associated with surgical remission in patients with acromegaly. The results showed that preoperative IGF-1 levels (odds ratio [OR], 1.004; 95\% confidence interval [CI], 1.000 to 1.008 ; $P=0.034)$ and cavernous sinus invasion (OR, 6.202; 95\% CI, 1.192 to $32.262 ; P=0.030)$ were significantly associated with surgical remission in patients with acromegaly. GNAS mutationnegative patients were less likely to experience surgical remission, although this correlation was not significant (OR, 0.1192; $95 \% \mathrm{CI}, 0.035$ to $1.058 ; P=0.058$ ) (Table 5).

\section{DISCUSSION}

In this study, we showed the prevalence of GNAS gene mutations in Korean patients with acromegaly and investigated the clinical characteristics and surgical remission rate of patients 
with GNAS mutations. GNAS mutations were found in $59.5 \%$ of patients, and most of them were located on codon 201 (86.7\%). GNAS mutation-positive tumors showed a high degree of GH staining and high hormone levels. The postoperative biochemical response and surgical remission rates were significantly more favorable in the mutation-positive patients.

GNAS encodes the alpha subunit of G protein with GTPase activity. GNAS mutations cause reduced GTPase activity, resulting in a constitutively active cAMP-dependent protein kinase A (PKA) pathway. This increases the level of activated PKA, which activates cAMP reactive element-binding protein in the nucleus and further activates the Pit- 1 transcription factor, promoting GH synthesis and cell proliferation [6,16,17]. Because GNAS is associated with GH synthesis and secretion, most studies have focused on GNAS mutations for drug responsiveness in acromegaly patients. After surgery, SSAs are considered the primary medical therapeutic agents in patients with persistent acromegaly [2]. However, one-third of patients treated with SSAs do not achieve biochemical remission [18]. Several genetic factors are involved in the response to SSA treatment. Most studies have reported that the therapeutic response to SSA is favorable in GNAS mutation-positive patients; the response has also been found to be significant in a meta-analysis [9]. Although this study did not analyze the response to SSAs, GNAS mutationpositive patients were biochemically controlled with cabergoline, which has been proven to be moderately effective in acromegaly. Several studies have also reported the tumor characteristics related to GNAS mutations. Some studies reported that tumors with GNAS mutations were smaller and less invasive than those without GNAS mutations [19,20]. In contrast, other studies have shown no significant difference in tumor size between tumors with and without GNAS mutations [21]. In our study, GNAS mutation-positive tumors showed no significant difference in size, but showed a greater degree of GH staining and higher IGF-1 secretion than mutation-negative tumors. Baseline GH levels were not significantly different between the GNAS mutation-positive and -negative groups, but the IGF-1 level was lower in the $G N A S$-negative group. This might be explained by the higher proportion of female patients in the GNAS-negative group and the influence of estrogen on hepatic IGF-1 synthesis [22,23].

Several clinical factors related to the surgical outcomes of acromegaly have been investigated. According to current guidelines [2], tumor size, preoperative GH concentration, and the experience of the pituitary surgeon are important for achieving successful surgery. In previous studies, extensive surgical resection could achieve a high surgical remission rate, and younger age, the female sex, cavernous sinus invasion, and sparsely granulated adenoma were related to poor surgical outcomes. In addition, the immediate postoperative GH level and 1-week postoperative OGTT GH levels were suggested as good predictors of surgical remission [15,24-27]. Few studies have compared surgical outcomes according to genetic alterations associated with acromegaly. In this study, the surgical remission rate of GNAS mutation-positive tumors was higher than that of mutation-negative tumors. There were more women among the GNAS mutation-negative patients, consistent with the previous findings that women show a poor prognosis [24].

One of the reasons for the high surgical remission rate of $G N A S$ mutation-positive tumors is that an early diagnosis is possible in such tumors due to high IGF-1 hormone secretion. On average, the diagnosis of acromegaly takes several years, because clinical symptoms are nonspecific and progress slowly [28]. Early recognition is important for achieving a high treatment success rate and avoiding long-term comorbidities [29]. $G N A S$ mutation-positive tumors tend to be smaller and show a higher cure rate because of the short time required for diagnosis. The percentage of patients who underwent total resection surgery for GNAS mutation-positive tumors was significantly higher than that of those who underwent total resection surgery for mutation-negative tumors. IHC staining results showed that tumors with $G N A S$ mutations mostly presented a high expression of $\mathrm{GH}$ in tumor tissues, in contrast to the frequent low expression of GH-positive cells in mutation-negative tumors. These results suggest that GNAS-mutant tumors are well-differentiated, which may enable efficient IGF-1 secretion, while mutation-negative tumors might have a heterogeneous cell population.

A major strength of this study is that it is the first to compare the surgical remission rate according to GNAS mutation status. Since only one senior neurosurgeon performed all operations, there was minimal bias related to the surgical technique or method. In addition, the findings of this study are significant in that recurrence and long-term outcomes were observed for more than 5 years after surgery. However, there are also some limitations to our study. Because this study was retrospective in nature and conducted at a single center, the number of patients was limited. Further prospective studies with a larger number of acromegaly patients could provide insights into the clinical significance of GNAS mutations and their relationship with surgical outcomes. Second, we performed Sanger sequencing targeting two known hotspot mutations. Some patients with GNAS mutations may have therefore been included in the GNAS-naïve group. Although numerous studies on GNAS have been per- 
formed, similar rates of GNAS mutation-positive tumors have been observed regardless of the method of genetic testing $[7,11,19,20,30,31]$, indicating that it is sufficient to analyze the hotspot mutations. Third, the granulation pattern was not analyzed. The granulation pattern of pituitary adenoma is considered an important determinant of prognosis and surgical remission [26,27]; hence, further study is needed.

In conclusion, we demonstrated the prevalence of GNAS mutations in Korean patients with acromegaly. GNAS mutations showed a distinct phenotype and high surgical remission rates. Identifying GNAS mutations would be helpful for predicting the clinical features and prognosis of patients with acromegaly after TSA.

\section{CONFLICTS OF INTEREST}

No potential conflict of interest relevant to this article was reported.

\section{ACKNOWLEDGMENTS}

This study was supported by a grant from the Korea Health Technology R\&D Project through the Korea Health Industry Development Institute funded by the Ministry of Health and Welfare, Republic of Korea (Grant HI14C1324 to Eun Jig Lee), and by the Basic Science Research Program through the National Research Foundation of Korea (NRF) funded by the Ministry of Education (NRF-2017R1D1A1B03033587 to Cheol Ryong $\mathrm{Ku})$.

\section{AUTHOR CONTRIBUTIONS}

Conception or design: C.R.K., E.J.L. Acquisition, analysis, or interpretation of data: H.J., K.K., D.K., J.H.M., E.H.K., S.H.K., C.R.K. Drafting the work or revising: H.J., C.R.K. Final approval of the manuscript: C.R.K., E.J.L.

\section{ORCID}

Hyein Jung https://orcid.org/0000-0001-8563-128X

Cheol Ryong Ku https://orcid.org/0000-0001-8693-9630

Eun Jig Lee https://orcid.org/0000-0002-9876-8370

\section{REFERENCES}

1. Melmed S. Acromegaly pathogenesis and treatment. J Clin
Invest 2009;119:3189-202.

2. Katznelson L, Laws ER Jr, Melmed S, Molitch ME, Murad MH, Utz A, et al. Acromegaly: an Endocrine Society clinical practice guideline. J Clin Endocrinol Metab 2014;99:393351.

3. Gadelha MR, Kasuki L, Korbonits M. The genetic background of acromegaly. Pituitary 2017;20:10-21.

4. Caimari F, Korbonits M. Novel genetic causes of pituitary adenomas. Clin Cancer Res 2016;22:5030-42.

5. Trivellin G, Daly AF, Faucz FR, Yuan B, Rostomyan L, Larco DO, et al. Gigantism and acromegaly due to Xq26 microduplications and GPR101 mutation. N Engl J Med 2014; 371:2363-74.

6. Landis CA, Masters SB, Spada A, Pace AM, Bourne HR, Vallar L. GTPase inhibiting mutations activate the alpha chain of Gs and stimulate adenylyl cyclase in human pituitary tumours. Nature 1989;340:692-6.

7. Landis CA, Harsh G, Lyons J, Davis RL, McCormick F, Bourne HR. Clinical characteristics of acromegalic patients whose pituitary tumors contain mutant Gs protein. J Clin Endocrinol Metab 1990;71:1416-20.

8. Lyons J, Landis CA, Harsh G, Vallar L, Grunewald K, Feichtinger $\mathrm{H}$, et al. Two $\mathrm{G}$ protein oncogenes in human endocrine tumors. Science 1990;249:655-9.

9. Efstathiadou ZA, Bargiota A, Chrisoulidou A, Kanakis G, Papanastasiou L, Theodoropoulou A, et al. Impact of gsp mutations in somatotroph pituitary adenomas on growth hormone response to somatostatin analogs: a meta-analysis. Pituitary 2015;18:861-7.

10. Freda PU, Chung WK, Matsuoka N, Walsh JE, Kanibir MN, Kleinman G, et al. Analysis of GNAS mutations in 60 growth hormone secreting pituitary tumors: correlation with clinical and pathological characteristics and surgical outcome based on highly sensitive GH and IGF-I criteria for remission. Pituitary 2007;10:275-82.

11. Hosoi E, Yokogoshi Y, Hosoi E, Horie H, Sano T, Yamada S, et al. Analysis of the Gs alpha gene in growth hormone-secreting pituitary adenomas by the polymerase chain reaction-direct sequencing method using paraffin-embedded tissues. Acta Endocrinol (Copenh) 1993;129:301-6.

12. Shi Y, Tang D, Deng J, Su C. Detection of gsp oncogene in growth hormone-secreting pituitary adenomas and the study of clinical characteristics of acromegalic patients with gsppositive pituitary tumors. Chin Med J (Engl) 1998;111:891-4.

13. Knosp E, Steiner E, Kitz K, Matula C. Pituitary adenomas with invasion of the cavernous sinus space: a magnetic reso- 
nance imaging classification compared with surgical findings. Neurosurgery 1993;33:610-7.

14. Micko AS, Wohrer A, Wolfsberger S, Knosp E. Invasion of the cavernous sinus space in pituitary adenomas: endoscopic verification and its correlation with an MRI-based classification. J Neurosurg 2015;122:803-11.

15. Ku CR, Kim EH, Oh MC, Lee EJ, Kim SH. Surgical and endocrinological outcomes in the treatment of growth hormone-secreting pituitary adenomas according to the shift of surgical paradigm. Neurosurgery 2012;71:ons192-203.

16. Hayward BE, Barlier A, Korbonits M, Grossman AB, Jacquet $P$, Enjalbert A, et al. Imprinting of the G(s)alpha gene GNAS1 in the pathogenesis of acromegaly. J Clin Invest 2001;107:R31-6.

17. Melmed S. Mechanisms for pituitary tumorigenesis: the plastic pituitary. J Clin Invest 2003;112:1603-18.

18. Colao A, Auriemma RS, Lombardi G, Pivonello R. Resistance to somatostatin analogs in acromegaly. Endocr Rev 2011;32:247-71.

19. Matsumoto R, Izawa M, Fukuoka H, Iguchi G, Odake Y, Yoshida K, et al. Genetic and clinical characteristics of Japanese patients with sporadic somatotropinoma. Endocr $\mathrm{J}$ 2016;63:953-63.

20. Barlier A, Gunz G, Zamora AJ, Morange-Ramos I, Figarella-Branger D, Dufour H, et al. Pronostic and therapeutic consequences of Gs alpha mutations in somatotroph adenomas. J Clin Endocrinol Metab 1998;83:1604-10.

21. Adams EF, Brockmeier S, Friedmann E, Roth M, Buchfelder M, Fahlbusch R. Clinical and biochemical characteristics of acromegalic patients harboring gsp-positive and gsp-negative pituitary tumors. Neurosurgery 1993;33:198203.

22. Leung KC, Johannsson G, Leong GM, Ho KK. Estrogen regulation of growth hormone action. Endocr Rev 2004;25: 693-721.
23. Shimon I, Barkan A. Estrogen treatment for acromegaly. Pituitary 2012;15:601-7.

24. Park SH, Ku CR, Moon JH, Kim EH, Kim SH, Lee EJ. Age- and sex-specific differences as predictors of surgical remission among patients with acromegaly. J Clin Endocrinol Metab 2018;103:909-16.

25. Kim EH, Oh MC, Lee EJ, Kim SH. Predicting long-term remission by measuring immediate postoperative growth hormone levels and oral glucose tolerance test in acromegaly. Neurosurgery 2012;70:1106-13.

26. Fougner SL, Casar-Borota O, Heck A, Berg JP, Bollerslev J. Adenoma granulation pattern correlates with clinical variables and effect of somatostatin analogue treatment in a large series of patients with acromegaly. Clin Endocrinol (Oxf) 2012;76:96-102.

27. Kiseljak-Vassiliades K, Carlson NE, Borges MT, Kleinschmidt-DeMasters BK, Lillehei KO, Kerr JM, et al. Growth hormone tumor histological subtypes predict response to surgical and medical therapy. Endocrine 2015;49: 231-41.

28. Melmed S. Medical progress: acromegaly. N Engl J Med 2006;355:2558-73.

29. Nachtigall L, Delgado A, Swearingen B, Lee H, Zerikly R, Klibanski A. Changing patterns in diagnosis and therapy of acromegaly over two decades. J Clin Endocrinol Metab 2008;93:2035-41.

30. Valimaki N, Demir H, Pitkanen E, Kaasinen E, Karppinen A, Kivipelto L, et al. Whole-genome sequencing of growth hormone $(\mathrm{GH})$-secreting pituitary adenomas. J Clin Endocrinol Metab 2015;100:3918-27.

31. Taboada GF, Tabet AL, Naves LA, de Carvalho DP, Gadelha MR. Prevalence of gsp oncogene in somatotropinomas and clinically non-functioning pituitary adenomas: our experience. Pituitary 2009;12:165-9. 